\title{
Anaesthesia Practice
}

\section{The Anaesthetic Services Programme Encompassing Nova Scotia (ASPENS)}

\begin{abstract}
A comprehensive peer review programme for anaesthesia departments in Nova Scotia was implemented in 1987 by the anaesthesia community. Departments are reviewed by peers at the request of the Head, Department of Anaesthesia, and the President of the Medical Staff. A confidential report with recommendations is written. Twenty-six reviews have been completed (to June 1993) and have most ofien documented deficiencies in: design of the anaesthesia record, anaesthesia staff recruitment, inadequate documentation of policies for anaesthesia and post-anaesthesia care, peer review/quality assurance processes, organizational structure of hospital medical staffs and operating room committees, and use of anaesthesia equipment that does not meet current (at date of review) CSA standards. In the four hospitals that have been reviewed twice, 24 of the 30 deficiencies noted on the first review had been corrected before the second review which occurred three to five years later. Nine new deficiencies were noted. Departments are encouraged to request a review every four or five years.
\end{abstract}

Un programme collégial d'auto-évaluation des départements d'anesthésie de la Nouvelle-Ecosse est entré en vigueur en 1987. Les départements sont évalués par les collègues du département d'anesthésie a la demande du chef du département et du président du personnel médical. Un rapport confidentiel avec recommandations est produit. Vingt-six révisions ont été complétées (jusqu'en juin 1993) et ont fait état des carences

\section{Key words}

ANAESTHESIA: department;

RECORDS: anaesthesia.

From the Department of Anaesthesia, Victoria General Hospital and Dalhousie University, Halifax, Nova Scotia, Canada.

Address correspondence to: Dr. A.J. Clark, Department of Anaesthesia, Victoria General Hospital, 1278 Tower Road, Halifax, Nova Scotia, Canada B3H 2 Y9.

Accepted for publication 30th April, 1994.

\section{A.J. Clark MD FRCPC}

suivantes dans: la conception du dossier anesthésique; le recrutement des professionnels; la documentation insuffisante des politiques concernant les soins anesthésiques et postanesthésiques; le processus collectif d'assurance de la qualité, les structures administratives des personnels médicaux et des comités de salles d'opérations, et l'utilisation d'appareils d'anesthésie qui ne rencontraient pas (au moment de linspection) les standards de Standards Canada. Dans les quatre hôpitaux révisés à deux reprises, 24 des 30 carences relevées à la première révision ont été corrigées avant la deuxieme révision réalisée de trois à quatre années plus tard. Neuf nouvelles carences ont été relevées. Les départements sont incités à faire une demande de révision à tous les quatre ou cing ans.

Traditionally, medical practices have only been peer reviewed when disasters have occurred and quality assurance programmes have frequently focused on "negative outcomes." Both processes tend to be unpleasant and demoralizing to those involved. ' Few medical specialties in Canada have developed peer review programmes of specific hospital departments or services which are conducted on an ongoing basis. ${ }^{2}$ However, peer review of individual medical practitioners has become much more common through the auspices of the provincial licensing bodies. ${ }^{3,4}$ Eagle and Davies have recently reviewed quality systems in health care, particularly as they relate to anaesthesia care and hospital accreditation. They observed that anaesthetists need to be aware of and familiar with the basic models of quality, and the terminology used. 5

In 1984 the Nova Scotia Division of the Canadian Anaesthetists' Society and the Section of Anaesthesia of the Medical Society of Nova Scotia recognized the need for a proactive programme to examine anaesthesia care in Nova Scotia whereby departments of anaesthesia, of hospitals located in the province, could be reviewed by their peers. Over the following two years the Anaesthetic Services Programme Encompassing Nova Scotia (ASPENS) 
was developed by the anaesthesia community and the programme was subsequently endorsed by the Medical Society of Nova Scotia. Agreement was obtained from the Department of Health to provide funding for the programme.

The funding provided for (a) a part-time coordinator (.2 FTE), (b) secretarial services, (c) travel, accommodation and honoraria for the review teams, (d) travel and accommodation for the meetings of the Action and the Planning and Directing Groups, and (e) sponsorship of a continuing medical education event (CME).

The objectives of ASPENS are to enhance the provision of anaesthesia and related care for all patients in Nova Scotia hospitals needing these medical services. The specific objectives of the programme, when initiated in 1987, were to:

1 provide a review system for departments of anaesthesia in Nova Scotia hospitals;

2 maintain a resource library of information relevant to anaesthesia;

3 have a "hot-line" system for urgent and emergency consultation, by telephone, for problems of patient management;

4 provide advice regarding: (a) the purchase of new anaesthesia and monitoring equipment, (b) problem solving of malfunctioning equipment, and (c) the promotion of the development of a service for urgent repairs and regular preventive maintenance;

5 promote and coordinate access to CME for anaesthetists.

\section{Structure}

The programme is carried out under the auspices and direction of the Section of Anaesthesia of the Medical Society of Nova Scotia. The part-time anaesthetist coordinator, initially Dr. Emerson Moffitt and currently Dr. John Clark, runs the programme with an office and secretarial support located in Halifax. The coordinator reports to the Action Group, to the Planning and Directing Group, and to the Section of Anaesthesia on behalf of the programme. The coordinator is appointed annually by the Section of Anaesthesia.

\section{The Planning and Directing Group}

The Planning and Directing Group functions in an advisory capacity to approve the broad objectives which are developed by the Action Group and to provide feedback to various stakeholders, i.e., Department of Health, Nova Scotia Allied Health Organization (NSAHO), Dalhousie University Faculty of Medicine, Section of Anaesthesia of the Medical Society of Nova Scotia.

The group meets annually to act in this advisory capacity, to review the activities of the Action Group, and to make suggestions to the Action Group as to future directions and activities of the programme.

The members of the group are (a) the programme coordinator, (b) the Head, Section of Anaesthesia, the Medical Society of Nova Scotia, (c) the Chair, Department of Anaesthesia, Dalhousie University, (d) the Administrator, Health Care Institutions, Department of Health, (e) an anaesthetist from a community hospital, (f) an anaesthetist from a regional hospital, and (g) a representative from NSAHO. At least one member of the above group must be a GP anaesthetist.

\section{The Action Group}

The Action Group develops the objectives of the programme, formulates and implements policies based on these objectives, oversees all activities of the programme, including reviews of departments of anaesthesia, and determines what activities the programme should continue or develop.

The membership of the Action Group was initially comprised of (a) the programme coordinator, (b) the Head, Section of Anaesthesia, the Medical Society of Nova Scotia, (c) a paediatric anaesthetist, (d) an obstetrical anaesthetist, (e) an intensive care anaesthetist, (f) an anaesthetist from each of the following regions - (i) Cape Breton, (ii) New Glasgow and Antigonish, (iii) Truro and Amherst, (iv) Kentville and Annapolis Valley, (v) Bridgewater and Liverpool, (vi) Yarmouth, Shelburne and Digby, (vii) Halifax and Dartmouth. In 1993 the number of regions was decreased by two with the amalgamation of (ii) and (iii) and of (v) and (vi) to reflect better the number of anaesthetists in each region.

The paediatric, obstetrical and intensive care anaesthetists may also be representatives from the regions, but the minimum number of Action Group members is seven, excluding the coordinator and the Head, Section of Anaesthesia.

The Action Group members are nominated by the Head, Section of Anaesthesia, after consultation with regional anaesthetists and the coordinator, and elected annually by the Section of Anaesthesia.

The Action Group meets twice yearly to oversee the programme and the coordinator reports directly to this group.

\section{Section of Anaesthesia, the Medical Society of Nova Scotia}

The Section of Anaesthesia is provided with an annual update by the coordinator of the current activities and status of the programme. This update is comprised of an outline of the reviews performed, the problems encountered and the recommendations made. The Section of Anaesthesia may also suggest items to be considered 
by the programme. The Section has complete control over the mandate of ASPENS and is responsible for any amendments to the document that outlines ASPENS and its functions. Any changes to the document, including composition of the Action or the Planning and Directing Groups, has to be approved by a majority vote of the Section. The document is a "living" document, i.e., it is continually being updated.

\section{The review process}

\section{Process}

The most visible component of ASPENS is the review process of departments of anaesthesia. This process was designed with several factors in mind.

1 A voluntary review. A request can only be made by the head of the department of anaesthesia and the president of the medical staff (or the equivalent, elected head of the medical staff); the review is not at the instigation, demand or request of the hospital administration.

$2 \mathrm{~A}$ means for the anaesthesia community to look at itself.

3 The composition of the review team allows for twoway feedback. The anaesthetists from teaching, regional and community hospitals performing the review are able to make suggestions and recommendations to the department being reviewed. At the same time, by performing the review, these individuals take back information and observations to their own hospital departments for possible integration and utilization. It is not a one-way system of a "group of experts" providing recommendations only.

4 To ensure the programme is perceived and operated as a province-wide advice and help system and not a centrally or "teaching hospital" run one.

When a review is requested, the coordinator forms a review team. Each team will usually consist of anaesthetists from teaching, regional, and community hospitals. This composition allows anaesthetists with different backgrounds, from several communities, to be involved. The head, department of anaesthesia, will provide the documentation that is given to the reviewers prior to the on-site visit (Table I). Since 1992 the head, department of anaesthesia, is also required to fill out a questionnaire concerning the department, its activities and facilities. Individual anaesthetists in the department also voluntarily complete a confidential questionnaire that details their educational background and current anaesthetic and CME activities.

The interviewing process is comprehensive and involves members of the hospital community from administration, nursing, and medical staff (Table II). Other
TABLE I Review of a department of anaesthesia

Documentation to be submitted before site visit

1 All policies and procedures for the department.

2 Hospital bylaws.

3 Requirements for granting anaesthesia privileges and their renewal.

4 Requirements for CPR education and activities of departmental members over the past two years.

5 Statement of staffing needs and strategy.

6 Evidence of audit and quality assurance programmes in the department.

7 Typical work schedule over a two-week period, call list.

8 Copies of the anaesthesia and recovery room records.

9 Evidence of monthly and annual case load: surgical, obstetrical. Breakdown of outpatient and inpatient case numbers.

10 Statement of involvement/coverage re: intensive care.

$11 \mathrm{CME}$ requirements and activities of department members.

12 Anaesthesia equipment maintenance summary for the previous two years.

13 Minutes of departmental meetings for past two years.

At the time of the survey (for review by reviewers)

1 A selection of anaesthesia/ recovery room records from the past year.

TABLE II Review of a department of anaesthesia

Interviews during the visit will be held with

(a) Department head

(b) Department members

(c) Chief of staff

(d) President of medical staff

(e) Head of surgery/surgical divisions

(f) Executive director

(g) Director of nursing

(h) OR supervisor

(i) Recovery room supervisor

(j) Other medical and hospital staff as deemed appropriate

members of the hospital.staff will also be interviewed if relevant to a particular department of anaesthesia. The head, department of anaesthesia, provides the review team with a narrative report of reasons for the review and concerns to be addressed.

The review is held over a one- to two-day period dependent upon the size of the hospital. The anaesthesia facilities (which include the operating rooms, recovery room, surgical day care unit, case room, intensive care unit(s), emergency department, and anaesthesia library) and the anaesthesia equipment are inspected. Allied services such as respiratory therapy, laboratories, transfusion services, etc., will be reviewed as necessary.

The Guidelines to the Practice of Anaesthesia, as recommended by the Canadian Anaesthetists' Society, ${ }^{6}$ the Guidelines for Anaesthetic Services in Nova Scotia, as endorsed by the Medical Society of Nova Scotia, ${ }^{7}$ and 


\section{TABLE III Review of a department of anaesthesia}

The Report

1.0 Preamble:

1.1 General philosophy of ASPENS reviews.

1.2 History of the development of anaesthesia services in the hospital including present status, caseload and anaesthesia personnel.

1.3 Reported concerns and problems noted prior to review.

2.0 Description of review (in list form only):

2.1 Documentation reviewed.

2.2 People interviewed.

2.3 Facilities inspected.

2.4 Allied services reviewed.

2.5 Debriefing.

3.0 Anaesthesia personnel - anaesthetists:

3.1 Training, qualifications and limitations.

4.0 Documentation, organization and functioning of the department:

4.1 Administrative structure of the department in relation to the hospital administration.

4.2 Written policies and procedures.

4.3 Hospital bylaws.

4.4 Requirements for granting privileges and their renewal.

4.5 CPR educational requirements.

4.6 CME requirements.

4.7 Staffing needs and strategy, workload, holidays, CME time

4.8 Work scheduling, and assignment of cases, call list, ICU, Obs coverage, pain activities.

4.9 Adequacy of anaesthesia services, administration/other medical services views, comments on performance, ability to handle caseloads.

4.10 Anaesthesia and recovery room records.

4.11 Audit and quality assurance programmes - peer review, chart review.

4.12 Depatmental organization - regular meetings, peer review, interaction with administration and other departments.

5.0 Physical plant and equipment:

5.1 Operating rooms.

5.2 Recovery room.

5.3 Case room.

5.4 Emergency department.

5.5 Intensive care unit(s).

5.6 Equipment (including resuscitation equipment).

5.7 Equipment service records.

5.8 Anaesthesia library facilities.

5.9 Anaesthesia office and staff.

6.0 Allied services:

6.1 Comments as/if necessary.

7.0 Summary of recommendations:

7.1 Organization

7.2 Policy

7.3 Staff

7.4 Equipment

7.5 Facilities

7.6 Long/short term

8.0 Overview and conclusion

- Recognition of assistance received.

the Canadian Standards Association (CSA) Standards ${ }^{8}$ are used as the basis for all reviews.

The chair of the review team is responsible for preparing a written summary of the review. The composition
TABLE IV Type of hospital/\# reviewed

\begin{tabular}{lcccl}
\hline & & \multicolumn{3}{c}{$\#$ Reviewed } \\
\cline { 4 - 5 } Hospital & 1987 & 1993 & Once & Twice \\
\hline Teaching & 5 & $4^{*}$ & 3 & 0 \\
Regional & 9 & $8 \dagger$ & 9 & 3 \\
Community & $\frac{12}{26}$ & $\frac{11 \ddagger}{23}$ & $\frac{10}{22}$ & $\frac{1}{4}$ \\
Total & 26 & 23 & 2 & 4 \\
\hline
\end{tabular}

*Two teaching hospitals amalgamated.

$\dagger$ Two regional hospitals amalgamated.

‡One regional and one community hospital amalgamated.

of the report is outlined (Table III). The coordinator is responsible for ensuring the consistency of recommendations of each review. The report is given, confidentially, to the Action Group representative, from the area in which the hospital is located, for comment. The final report is sent to the head, department of Anaesthesia, and to the president of the medical staff of the hospital involved. These two individuals decide the distribution of the report within the hospital.

In 1993 changes were made in the way the report was handled. After the initial draft is formulated, it is also sent to the head, department of anaesthesia, for comment in regards to accuracy, before the final report is completed. In addition, the report is now also provided to the medical director, or equivalent person (i.e., the administration), upon completion.

When a repeat review is undertaken, the original report and recommendations will be given to the review team prior to the review.

\section{Findings}

Nova Scotia had 26 hospitals providing anaesthesia services when the programme started in 1987. As of May 1993, there are 23 hospitals. Eighteen departments have been reviewed once and four departments have undergone two reviews (Table IV). The number of anaesthetics administered in each hospital ranged from 270 to 19,600 services per year, and the number of anaesthetists varied from 1 to 28 . The three departments not reviewed have requested reviews. Thirty-six anaesthetists have acted as reviewers. The total number of anaesthetists (1993), specialist and non-specialist, in Nova Scotia is 93, of whom 81 are full-time or full-time equivalent practitioners (Table V). Deficiencies identified during the reviews are presented in Table VI. The deficiencies have been grouped by category to reflect administrative, equipment, staffing, facilities, anaesthesia record, CME policy, and miscellaneous problems encountered.

The areas most often identified as deficient were the anaesthesia record design, anaesthesia recruitment, writ- 
TABLE V Anaesthesia manpower - Nova Scotia, 1993

\begin{tabular}{|c|c|c|c|c|c|}
\hline \multirow[b]{2}{*}{ Hospital } & \multicolumn{2}{|l|}{ Part-time } & \multicolumn{2}{|l|}{ Full-time } & \multirow[b]{2}{*}{ Acted as reviewer } \\
\hline & Specialist & Other* & Specialist & Other* & \\
\hline Teaching & 2 & 0 & 49 & 0 & 16 \\
\hline Regional & 0 & 0 & 16 & 12 & 13 \\
\hline Community & $\underline{0}$ & $\underline{10}$ & 4 & $\underline{0}$ & 7 \\
\hline Total & 2 & 10 & 69 & 12 & 36 \\
\hline
\end{tabular}

*Not recognized as specialists by the Provincial Medical Board of Nova Scotia.

TABLE VI Hospitals reviewed, 1987-1993 - Major deficiencies requiring action

\begin{tabular}{|c|c|c|c|}
\hline & \multicolumn{3}{|l|}{ Hospital type } \\
\hline & Community & Regional & Teaching \\
\hline Number of reviews & $11^{*}$ & $12 \dagger$ & 3 \\
\hline \multicolumn{4}{|l|}{ Administrative deficiencies } \\
\hline Medical staff organization & 6 & 4. & 2 \\
\hline OR committee & 4 & 6 & 1 \\
\hline Departmental structure/meetings & 5 & 5 & 1 \\
\hline Policies - none/few & 6 & 7 & 2 \\
\hline Peer review/Q.A. - inadequate & 10 & 4 & 0 \\
\hline \multicolumn{4}{|l|}{ Equipment deficiencies } \\
\hline Anaesthesia machine & 2 & 2 & 1 \\
\hline Anaesthesia ventilator & 7 & 4 & 1 \\
\hline Other, i.e., alarms, oximeters, ECG, capnography & 7 & 4 & 2 \\
\hline Servicing of equipment & 3 & 1 & 0 \\
\hline \multicolumn{4}{|l|}{ Staffing inadequacies } \\
\hline Post-anaesthesia care unit & 3 & 4 & 0 \\
\hline Anaesthesia recruitment & 7 & 5 & 3 \\
\hline Anaesthesia on-call coverage & 2 & 5 & 0 \\
\hline ICU/OBS/pain coverage & 0 & 3 & 3 \\
\hline \multicolumn{4}{|l|}{ Physical facilities } \\
\hline Operating rooms & 0 & 2 & 0 \\
\hline Post-anaesthesia care unit & 3 & 2 & 0 \\
\hline Anaesthesia library & 5 & 3 & 2 \\
\hline \multicolumn{4}{|l|}{ Anaesthesia record } \\
\hline Design & 9 & 7 & 1 \\
\hline Completion by anaesthetist & 3 & 2 & 1 \\
\hline \multicolumn{4}{|l|}{ CME policy } \\
\hline No hospital/departmental policy & 7 & 7 & 1 \\
\hline \multicolumn{4}{|l|}{ Miscellaneous deficiencies } \\
\hline Neonatal resuscitation (OBS) & 4 & 2 & 0 \\
\hline Inadequate preop rounds & 2 & 1 & 0 \\
\hline Inadequate narcotic control & 1 & 0 & 0 \\
\hline Privileges & 1 & 0 & 0 \\
\hline Lack of financial support & 1 & 3 & 0 \\
\hline Interpersonal communication & 1 & 3 & 1 \\
\hline
\end{tabular}

*One hospital - two reviews.

†Three hospitals - two reviews. 
ten policies related to anaesthesia and post-anaesthesia care, peer review/quality assurance processes, poor hospital medical staff/departmental structure, CME policies, and anaesthesia equipment.

The design of the anaesthesia record was judged to be poor in 17 of the departments reviewed. The layout of the record did not allow for sequencing of events during anaesthesia; there was lack of space to provide relevant information of events during anaesthesia which made it impossible to determine when drugs or fluids were administered during anaesthesia or when other procedures were performed by the anaesthetist. Community hospitals frequently had more inadequate anaesthesia records than regional or teaching hospitals.

Anaesthesia recruitment was an issue in all types of hospitals. The teaching hospitals had problems with recruitment because of the change in demand for anaesthesia services as a result of budgetary impact on the provision of hospital based health care. In the community and regional hospitals, the issue of recruitment centred around the volume of work available within the institution. Often there would only be enough work for an extra part-time anaesthetist but not a full-time anaesthetist, but at the same time there was too much work for the present complement of anaesthetists. Four regional or community hospitals provided salary support or guaranteed minimum incomes to their anaesthetists. Most other hospitals and the Department of Health have been unwilling to consider this to facilitate better recruitment and staffing.

Written policies relating to anaesthesia and postanaesthesia care were either non-existent, outdated, or incomplete in 15 of the 26 reviews. All types of hospitals had deficiencies noted. Written policies that were looked for included: (1) patient identification in OR; (2) patient selection for day care surgery; (3) patient monitoring during surgery; (4) verification and administration of blood products; (5) care and cleaning of anaesthetic equipment; (6) regular monitoring of $\mathrm{OR}$ anaesthetic gas pollution; (7) electrical safety; (8) fire; (9) use of intravenous narcotics in recovery room; (10) discharge criteria for recovery room to ward/home; (11) maintenance of epidurals for postoperative analgesia; and (12) attendance of an anaesthetist for all/high risk deliveries.

Peer review and quality assurance processes were nonexistent or very minimal in all the community hospitals on their initial review. The teaching hospitals had well developed peer review/QA processes, whereas the larger regional hospitals also tended to have well functioning programmes.

The administrative processes of the hospital as they related to the medical staff organization were deficient in 12 of the hospitals reviewed. This led to poor com- munication between the Department of Anaesthesia and the administration. Almost all of these hospitals also had operating room committees that either did not exist or functioned very poorly with the consequent lack of decision-making. Health professionals in surgery, anaesthesia, and nursing frequently lacked a forum to express and discuss concerns when there was no functioning operating room committee. In five reviews this had led to severe problems in interpersonal communications.

Departmental structure and function was considered to be inadequate in 11 of 26 reviews. This consisted of a lack of departmental meetings, either because the department only consisted of one to three members, or it was difficult to schedule meetings because of clinical commitments, and thus meetings tended not to be held.

Policies about CME were non-existent at the beginning of the reviews in 1987; however, in the interim, several hospitals have developed CME policies for active staff members. Policies, either on a hospital or a departmental basis, did not exist in 15 of 26 hospitals reviewed.

Equipment used during anaesthesia (excluding the ventilators) was judged not to be in keeping with CSA standards in five hospitals. The recommendation was made in these situations that the anaesthesia machines be replaced and not used further. Anaesthesia ventilators were judged not to meet CSA standards in 12 different reviews. In seven of these reviews ventilators with hanging bellows were being used. Deficiencies with other ancillary equipment such as alarms, oximeters, electrocardiograms, capnography equipment, etc., occurred in two instances where equipment available for anaesthesia did not meet the Canadian Anaesthetists' Society guidelines, and in all other situations it related to equipment reaching the end of its usable life span. Servicing of anaesthesia equipment was rarely a problem.

Staffing of the post-anaesthesia care unit was an issue in seven of the community and regional hospitals. Coverage during out of hours was judged to be inadequate if only one nurse was available to observe recovery of patients following anaesthesia. Three hospitals did not provide special training or require previous training in the recovery of patients prior to a nurse being assigned to the post-anaesthesia care unit.

The operating room facilities were considered to be inadequate and too small for the types of cases being performed in two hospitals. Both these hospitals were older hospitals that were moving to new facilities shortly after the reviews were completed. Five hospitals had inadequate space for the recovery of patients in the postanaesthesia care unit, with consequent delays in the operating room schedule. Ten departments had either no anaesthesia library or facilities to keep anaesthesia reference materials close at hand to the operating room. 
TABLE VII Hospitals reviewed twice 1987-1993. Deficiencies noted on first review and corrected before second review and new deficiencies at second review

\begin{tabular}{|c|c|c|c|c|c|c|}
\hline & \multicolumn{6}{|c|}{ Hospital type } \\
\hline & \multicolumn{3}{|c|}{ Community } & \multicolumn{3}{|c|}{ Regional } \\
\hline \multirow[t]{4}{*}{ Number of reviews } & \multicolumn{3}{|l|}{1} & \multicolumn{3}{|l|}{3} \\
\hline & \multicolumn{3}{|c|}{ Deficiencies } & \multicolumn{3}{|c|}{ Deficiencies } \\
\hline & \multicolumn{3}{|c|}{ Corrected } & \multicolumn{3}{|c|}{ Corrected } \\
\hline & Yes & No & New & Yes & No & New \\
\hline \multicolumn{7}{|l|}{ Administrative } \\
\hline Medical staff organization & 0 & 0 & 0 & 1 & 0 & 0 \\
\hline OR committee & 0 & 0 & 0 & 0 & 1 & 0 \\
\hline Departmental structure/meetings & 0 & 0 & 0 & 1 & 0 & 1 \\
\hline Policies - none/few & 1 & 0 & 0 & 1 & 1 & 0 \\
\hline Peer review/QA - inadequate & 0 & 1 & 0 & 1 & 0 & 0 \\
\hline \multicolumn{7}{|l|}{ Equipment } \\
\hline Anaesthesia machine & 0 & 0 & 0 & 0 & 0 & 1 \\
\hline Anaesthesia ventilator & 1 & 0 & 0 & 2 & 0 & 1 \\
\hline \multicolumn{7}{|l|}{ Other, i.e., alarms, oximeters, } \\
\hline ECG, capnography & $\cdot 0$ & 0 & 1 & 0 & 1 & 1 \\
\hline Servicing of equipment & 1 & 0 & 0 & 0 & 0 & 0 \\
\hline \multicolumn{7}{|l|}{ Slaffing inadequacies } \\
\hline Post-anaesthesia care unit & 0 & 0 & 0 & 1 & 0 & 1 \\
\hline Anaesthesia recruitment & 1 & 0 & 1 & 1 & 0 & 0 \\
\hline Anaesthesia on-call coverage & 0 & 0 & 0 & 1 & 0 & 0 \\
\hline ICU/OBS/pain coverage & 0 & 0 & 0 & 1 & 0 & 0 \\
\hline \multicolumn{7}{|l|}{ OR record } \\
\hline Design & 0 & 1 & 0 & 2 & 1 & 0 \\
\hline Completion by anaesthetist & 1 & 0 & 0 & 0 & 0 & 1 \\
\hline \multicolumn{7}{|l|}{ CME policy } \\
\hline No hospital/departmental policy & 0 & 0 & 0 & 3 & 0 & 0 \\
\hline \multicolumn{7}{|l|}{ Miscellaneous } \\
\hline Neonatal resuscitation (OBS) & 0 & 0 & 1 & 0 & 0 & 0 \\
\hline Financial support & 0 & 0 & 0 & 2 & 0 & 0 \\
\hline Interpersonal communication & $\underline{0}$ & $\underline{0}$ & $\underline{0}$ & $\underline{2}$ & $\underline{0}$ & $\underline{0}$ \\
\hline Total & 5 & 2 & 3 & 19 & 4 & 6 \\
\hline
\end{tabular}

In six reviews, completion of the anaesthetic chart by anaesthesia staff was judged to be inadequate as compared to the recommendations of the Canadian Anaesthetists' Society Guidelines to the Practice of Anaesthesia. Neonatal resuscitation procedures for Caesarean sections was judged to be deficient on six reviews when only the anaesthetist was available to resuscitate the infant. Inadequate narcotic control and inappropriate provision of privileges in anaesthesia were noted in one instance each.

The full report of the review was provided to the department and the administration of the hospital by the head of anaesthesia and/or the president of the medical staff in all except two cases. The two exceptions have been at the individual decision of the head of anaesthesia. In both hospitals many deficiencies were noted.

Four hospitals have undergone a second review, three regional and one community. Twenty-four deficiencies noted on the initial review had been corrected at the time of the second review. Six deficiencies continued to be uncorrected and nine new deficiencies were noted on the second review that had not been present during the first review (Table VII). 


\section{Other activities}

The programme has several other activities.

\section{Newsletter}

A Newsletter is published once or twice yearly dealing with points of interest to anaesthetists in Nova Scotia. Specific emphasis is placed on quality assurance/risk management. In addition, the telephone numbers for emergency consultation are published to allow for consultation with paediatric, obstetrical, or general anaesthetists in Halifax.

\section{Educational programme}

An educational programme is held on a yearly basis. These have varied between traditional, didactic, CME presentations (previously) and workshops (recently) on standards of practice, quality assurance, fibreoptic intubation, and regional anaesthesia. A library of videotapes is available for loan throughout the province.

\section{Anaesthesia record}

One of ASPENS major objectives had been to develop standardized anaesthesia and post-anaesthesia care unit forms that could be used throughout the province. The results of the reviews support this need. This has proved to be difficult. A document has been produced providing many of the important qualities of an anaesthesia and post-anaesthesia care unit record. ${ }^{9}$ This record has been made available to all departments of anaesthesia in Nova Scotia for their information.

\section{Development of quality assurance programmes in small hospitals}

A recognized deficiency in many of the smaller hospitals reviewed has been the lack of quality assurance programmes. The development of quality assurance programmes has been encouraged. A critical incident reporting system has been developed that can be utilized within hospitals and also compared among different hospitals or summated when groups of anaesthetists are providing anaesthesia services to several different hospitals. This process will continue to be facilitated by ASPENS.

\section{Advice regarding anaesthesia and monitoring equipment}

This objective of the programme has been the most difficult to deal with. In practice ASPENS has never been able to provide this service, but has been able to facilitate the transfer of information to individual departments as needed.

\section{Conclusion}

The review process through the ASPENS programme has highlighted areas of deficiencies in anaesthesia departments in Nova Scotia. The most frequently cited deficiencies are: design of the anaesthesia record, difficulty in anaesthesia staff recruitment, lack of peer review/quality assurance programmes, inadequate written policies relating to anaesthesia and post-anaesthesia care, poor organizational structure of medical staff organizations and of the operating room units, and use of anaesthesia equipment that does not meet CSA standards. This has led to initiatives by the programme to improve the design of anaesthesia records available in Nova Scotia, and to enhance and facilitate development of quality assurance programmes. The programme has provided information from the reviews to the Section of Anaesthesia of the Medical Society of Nova Scotia, which has been able to utilize the information in its negotiations and discussions with the Medical Society and Department of Health.

Results from the four departments that have been reviewed a second time indicate that the reviews played a useful role as 24 of the 30 deficiencies noted on the original reviews had been addressed prior to the second review. Only nine new deficiencies were noted on the second review that had not been present on the previous review. These findings suggest that the programme is beneficial to the anaesthesia community in Nova Scotia. This mirrors the feedback that has been received by the Action Group from anaesthetists around the province and from the Section of Anaesthesia.

The advent of peer review of individual practitioners, sponsored by the provincial licensing bodies, will not reduce the continued need for peer review of departments of anaesthesia. ASPENS can continue to highlight and provide valuable information about problems and deficiencies facing departments of anaesthesia in Nova Scotia. This allows the anaesthesia community to be pro-active in providing the best possible care for patients. Currently discussions are ongoing among the anaesthesia community, the surgical community, and the Department of Health about a surgical programme that would mirror the Anaesthetic Services Programme Encompassing Nova Scotia.

\section{Acknowledgements}

I would like to thank Polly Moores and Jan Scott for preparation of this manuscript and the members of the Action Group of ASPENS for their help and support.

\section{References}

1 Duncan P. Quality: a job well done! (Editorial). Can J Anaesth 1993; 40: 813-5.

2 Luther ER Regionalization of perinatal care. Journal of 
the Society of Obstetricians and Gynaecologists of Canada 1990; 12: 3-5.

3 McAuley RG, Paul WM, Morrison GH, Beckett RF, Goldsmith $C H$. Five-year results of the peer assessment program of the College of Physicians and Surgeons of Ontario. Can Med Assoc J 1990; 143: 1193-9.

4 Ellis $M W$, O'Connor JF. Peer review and maintenance of competence in Nova Scotia. The Nova Scotia Medical Journal 1991; 70: 105-8.

5 Eagle CJ, Davies JM. Current models of "quality" - an introduction for anaesthetists. Can J Anaesth 1993; 40: 851-62.

6 Guidelines to the Practice of Anaesthesia. Canadian Anaesthetists' Society. Toronto, 1993.

7 Guidelines for Anaesthetic Services in Nova Scotia. The Medical Society of Nova Scotia. Dartmouth, 1987.

8 A National Standard of Canada, Series Z168, 303 and 305. Canadian Standards Association. Rexdale. 1982-1992.

9 Gravenstein JS. The uses of the anaesthesia record. J Clin Monit 1989; 5: 256-65. 